\title{
The Relationships between Neutrophil/Lymphocyte Ratio and Child-Turcotte-Pugh Classification in Assessing Severity of Liver Cirrhosis
}

\author{
Griselda $^{1}$, Kemas Ya'kub Rahadiyanto ${ }^{2}$, Rachmat Hidayat ${ }^{3 \#}$ \\ ${ }^{1}$ Undergraduate Student, Faculty of Medicine, Universitas Sriwijaya \\ ${ }^{2}$ Clinical Pathology Department, Faculty of Medicine, Universitas Sriwijaya \\ ${ }^{3}$ Biology Department, Faculty of Medicine, Universitas Sriwijaya \\ *Corresponding Author E-mail: dr.rachmat.hidayat@gmail.com \\ Received : November $17^{\text {th }} 2018$ \\ Accepted :January 29th 2019
}

\section{Background}

Liver cirrhosis is a disease with high morbidity and mortality in Indonesia. The Child-Turcotte-Pugh classification is a noninvasive parameter to assess severity of liver cirrhosis. Meanwhile, the neutrophil/lymphocyte ratio can reflect person's immunity to liver cirrhosis.

\section{Objective}

This study was conducted to determine the conformity between neutrophil/lymphocyte ratio and Child-Turcotte-Pugh classification in assessing severity of liver cirrhosis.

\section{Methods}

Analytical observational study with Cohen's Kappa conformity test was conducted in 86 liver cirrhosis patients. Data was retrieved by observing the medical records. Neutrophil count, lymphocyte count, hepatic encephalopathy, ascites, albumin, bilirubin, and INR were all recorded. Documented variables were analyzed by the Cohen's Kappa conformity test.

\section{Results}

In Cohen's Kappa conformity test, there was moderate conformity between neutrophil/lymphocyte ratio and ChildTurcotte-Pugh classification in all samples $(\kappa=0.591$ and $\mathrm{p}<0.001)$. Conformity between neutrophil/lymphocyte ratio and Child-Turcotte-Pugh classification based on age and gender was found to be $\kappa=0.777$ at age $\leq 45$ years, $\kappa=0.532$ at age $>45$ years, $\kappa=0.682$ in male, and $\kappa=0.445$ in female $(\mathrm{p}<0.001)$. The highest conformity is the substantial conformity between neutrophil/lymphocyte ratio and Child-Turcotte-Pugh classification obtained at age $\leq 45$ years $(\kappa=0.777$ and $\mathrm{p}<0.001)$ and male $(\kappa=0.682$ and $\mathrm{p}<0.001)$.

\section{Conclusion}

There is moderate conformity between neutrophil/lymphocyte ratio and Child-Turcotte-Pugh classification in assessing severity of liver cirrhosis. Substantial conformity obtained at age $\leq 45$ years and male gender.

Keywords: Neutrophil/Lymphocyte Ratio, Child-Turcotte-Pugh, Liver Cirrhosis 


\section{ISSN 25980580}

\section{Background}

Liver cirrhosis is the final stage of the diffuse process of progressive liver fibrosis characterized by distortion of liver architecture and regenerative nodule formation. Liver cirrhosis is the third highest cause of death in patients aged 45-46 years ${ }^{[1]}$. In 2017, there were 45,783,000 cases of liver cirrhosis in the world and 1,638,000 of them were new cases. ${ }^{[2]}$

Indonesia is one of ten developing countries with the highest cases of liver cirrhosis according to the World Health Organization (WHO). ${ }^{[3-4]}$ The prevalence of liver cirrhosis in Indonesia in 2007 was $1.7 \%$ and increased to $3.5 \%$ in $2013 .^{[5-6]}$ Recent data recorded the mortality rate of liver cirrhosis in Indonesia according to gender by $52.7 / 100,000$ population in men and $16.6 / 100,000$ population in women. ${ }^{[4]}$

Neutrophil/lymphocyte ratio is a parameter that can reflect a person's immunity against liver cirrhosis because neutrophils and lymphocytes play an important role in the course of the disease of liver cirrhosis. ${ }^{[7-10]}$ The neutrophil/lymphocyte ratio is a cheap, available and fast method to describe systemic inflammation, as well as complex pathophysiological processes that underlie the progression of liver cirrhosis. ${ }^{[11-15]}$ However, an increase in the neutrophil/lymphocyte ratio is not only found in patients with liver cirrhosis, but it is also found in patients suffering from infections, autoimmune diseases, HIVAIDS, malignancy, leukemia, or being pregnant so that the neutrophil/lymphocyte ratio cannot used if the patient with cirrhosis of the liver suffers from one of the accompaniers. ${ }^{[16]}$ The neutrophil/lymphocyte ratio is obtained from laboratory results with a complete blood examination. The neutrophil/lymphocyte ratio can be calculated by dividing absolute neutrophil counts with absolute lymphocytes. [17]

The severity of liver cirrhosis can be measured using an objective, accurate and inexpensive scoring system such as the Child-Turcotte-Pugh classification and the Model of End-Stage Liver Disease (MELD). ${ }^{[11,18-19]}$ The Child-Turcotte-Pugh classification and MELD have similar prognosis significance in many cases. ${ }^{[20-21]}$ However, in a recent study it was found that the Child-Turcotte-Pugh classification was intended to assess survival while MELD was intended to determine the optimal time for liver 


\section{ISSN 25980580}

transplantation. ${ }^{[22]}$ Therefore, the Child-Turcotte-Pugh scoring system can be used to measure the severity associated with the survival of patients with liver cirrhosis.

In previous studies it was found that the neutrophil/lymphocyte ratio was significantly useful for predicting the prognosis of patients with liver cirrhosis. ${ }^{[23-25]}$ The study was supported by research in Indonesia with a significant positive correlation between neutrophil/lymphocyte ratio and ChildTurcotte-Pugh scores in patients with liver cirrhosis $(r=0.749$ and $p<0.0001)$. [11]

Liver cirrhosis is a disease that has a poor prognosis and Indonesia is one of the developing countries with high rates of morbidity and mortality of liver cirrhosis. ${ }^{[26]}$ Therefore, a study was conducted on the conformity test between the neutrophil/lymphocyte ratio and the Child-Turcotte-Pugh classification in assessing severity of liver cirrhosis in RSUP Dr. Mohammad Hoesin Palembang.

The purpose of this study was to determine the conformity between the neutrophil/lymphocyte ratio and the Child-Turcotte-Pugh classification in assessing severity of liver cirrhosis. Identification of neutrophil/lymphocyte ratios and Child-Turcotte-Pugh classification in patients with liver cirrhosis in Indonesia can also illustrate the importance of improving early detection, early management and communication, information as well as education regarding the importance of treatment to prevent worsening of liver cirrhosis.

\section{Methods}

This study was an observational analytic study using the Cohen's Kappa conformity test conducted from January 2016 to October 2018. ${ }^{[27-28]}$ The sample of this study was all liver cirrhosis patients who had undergone complete blood tests and liver function examinations during the period of January 2016 to October 2018 at RSUP Dr. Mohammad Hoesin Palembang who fulfilled the inclusion criteria. The inclusion criteria are all patients aged 18-65 years old who had been diagnosed with liver cirrhosis by a Gastroenterology and Hepatology specialist. Patients necessarily had undergone complete blood tests and liver function examination during the period of January 2016 to October 2018 in the Internal Medicine Installation of RSUP Dr. Mohammad Hoesin Palembang. 


\section{ISSN 25980580}

The research data was obtained from the patients' medical records. Factors studied included neutrophil count, lymphocyte count, hepatic encephalopathy, ascites, albumin, bilirubin, and INR. Diagnosis of liver cirrhosis is seen through diagnosis results in medical records.

Univariate analysis was used to determine the characteristics of patients with liver cirrhosis based on age and gender. In addition, the distribution of patients was based on cut-off point from neutrophil/lymphocyte ratio and Child-Turcotte-Pugh classification. The bivariate analysis used was the Cohen's Kappa test to determine the conformity of neutrophil/lymphocyte ratio and Child-Turcotte-Pugh classification.

\section{Results}

Research had been conducted at RSUP Dr. Mohammad Hoesin Palembang and it was found that there were 297 liver cirrhosis patients from January 1, 2016 - October 31, 2018. Eighty six out of 297 samples met the inclusion and exclusion criteria.

Table 1. Liver Cirrhosis Patients Data $(\mathbf{n}=\mathbf{8 6})$

\begin{tabular}{|l|c|c|}
\hline \multicolumn{1}{|c|}{ Characteristics } & $\mathbf{n}$ & $\mathbf{\%}$ \\
\hline Age & & 22 \\
\hline$\leq 45$ years old & 64 & $74.4 \%$ \\
\hline$>45$ years old & & \\
\hline Gender & 54 & $62.8 \%$ \\
\hline Male & 32 & $37.2 \%$ \\
\hline Female & & \\
\hline BMI & 2 & $2.3 \%$ \\
\hline$<17.0$ & 13 & $15.1 \%$ \\
\hline $17.0-18.4$ & 56 & $65.1 \%$ \\
\hline $18.5-25.0$ & 4 & $4.7 \%$ \\
\hline $25.1-27.0$ & 11 & $12.8 \%$ \\
\hline$>27.0$ & & \\
\hline Etiology (Hepatitis) & 44 & $51.2 \%$ \\
\hline Hepatitis B & 5 & $5.8 \%$ \\
\hline Hepatitis C & 2 & $2.3 \%$ \\
\hline Hepatitis B dan C & 35 & $40.7 \%$ \\
\hline Not Hepatitis & & \\
\hline
\end{tabular}


ISSN 25980580

Table 1 shows the characteristics of liver cirrhosis patients. Patients with liver cirrhosis in this study were aged 25-65 years old. The mean \pm SD age of liver cirrhosis patients is $51 \pm 8.54$ years old. Based on gender, men dominate with a percentage of $62.8 \%$. BMI of liver cirrhosis patients had a mean $\pm \mathrm{SD}$ of $22.04 \pm 4.24 \mathrm{~kg} / \mathrm{m}^{2}$ and is dominated by patients with normal BMI (18.5-25.0). Meanwhile, the main etiology of patients with liver cirrhosis in Asia is hepatitis B and C infection so that hepatitis B infection is the highest in this study (51.2\%). Liver cirrhosis patients with hepatitis B and C infections were obtained based on laboratory tests, namely $\mathrm{HBsAg}$ and anti-HCV.

Table 2. Distribution of Major Complaint in Patients $(\mathbf{n}=\mathbf{8 6})$

\begin{tabular}{|l|c|c|}
\hline \multicolumn{1}{|c|}{ Major Complaint } & n & \% \\
\hline Enlarged stomach & 31 & $36.0 \%$ \\
\hline Black vomit and feces & 15 & $17.4 \%$ \\
\hline Limp body & 14 & $16.3 \%$ \\
\hline Black feces & 10 & $11.6 \%$ \\
\hline Stomach cramp & 9 & $10.5 \%$ \\
\hline Black vomit & 3 & $3.5 \%$ \\
\hline Loss of consciousness & 3 & $3.5 \%$ \\
\hline Icteric & 1 & $1.2 \%$ \\
\hline
\end{tabular}

In table 2, distribution of the main complaints showed that the most major complaints in liver cirrhosis patients who came to RSUP Dr. Mohammad Hoesin Palembang was enlarged stomach (31 patients), black vomit and feces (15 patients), and limp body (14 patients). This main complaint is in accordance with the clinical findings presented in table 3. 
ISSN 25980580

Table 3. Distribution of Clinical Findings in Patients ( $\mathbf{n = 8 6})$

\begin{tabular}{|l|c|c|}
\hline \multicolumn{1}{|c|}{ Clinical Findings } & $\mathbf{n}$ & $\mathbf{\%}$ \\
\hline Esophageal Varices & & $41.9 \%$ \\
\hline Esophageal Varices & 36 & $58.1 \%$ \\
\hline Not Esophageal Varices & 50 & \\
\hline Hepatic Encephalopathy & & $11.6 \%$ \\
\hline Hepatic Encephalopathy & 10 & $88.4 \%$ \\
\hline Not Hepatic Encephalopathy & 76 & \\
\hline Ascites & & $58.1 \%$ \\
\hline Ascites & 50 & $41.9 \%$ \\
\hline Not Ascites & 36 & \\
\hline
\end{tabular}

The distribution of clinical findings in patients with liver cirrhosis is presented in table 3. Clinical findings in the form of esophageal varices, hepatic encephalopathy, and ascites are a form of hepatocellular failure and portal hypertension in patients with liver cirrhosis.

Table 4. Distribution of Neutrophil/Lymphocyte Ratio and Child-Turcotte-Pugh Classification in Patients (n=86)

\begin{tabular}{|l|c|c|}
\hline \multicolumn{1}{|c|}{ Variable } & n & \% \\
\hline Neutrophil/Lymphocyte Ratio & & $24.4 \%$ \\
\hline$\leq 3,1482$ & 21 & $51.2 \%$ \\
\hline $3,1483-6,5208$ & 44 & $24.4 \%$ \\
\hline$\geq 6,5209$ & 21 & \\
\hline Child-Turcotte-Pugh Classification & & $22.1 \%$ \\
\hline Child-Turcotte-Pugh A & 19 & $38.4 \%$ \\
\hline Child-Turcotte-Pugh B & 33 & $39.5 \%$ \\
\hline Child-Turcotte-Pugh C & 34 & \\
\hline
\end{tabular}

Table 4 shows the distribution of neutrophil/lymphocyte ratio and the mean \pm SD in liver cirrhosis patients obtained is $4.77 \pm 2.016$. The minimum value of the neutrophil/lymphocyte ratio obtained was only 1.22 and the maximum value of the neutrophil/lymphocyte ratio obtained was 9.67 . The cut-off point of neutrophil/lymphocyte ratio in liver cirrhosis patients was based on the $25^{\text {th }}$ and $75^{\text {th }}$ percentiles of IBM SPSS Statistic 23. Meanwhile, table 4 also presents the distribution of the Child-Turcotte-Pugh classification and it was found that liver cirrhosis patients in this study dominated by Child-Turcotte- 
ISSN 25980580

Pugh C classification (39.5\%). The Child-Turcotte-Pugh classification is determined based on the parameters for hepatic encephalopathy, ascites, albumin, bilirubin, and INR.

Table 5. Conformity between Neutrophil/Lymphocyte Ratio and Child-Turcotte-Pugh Classification in Assessing Severity of Liver Cirrhosis

\begin{tabular}{|l|c|c|}
\hline \multicolumn{1}{|c|}{ Agreement } & $\boldsymbol{\kappa}$ & $\boldsymbol{p}_{\text {_value }}$ \\
\hline All Samples & 0.591 & 0.000 \\
\hline Age & & 0.000 \\
\hline$\leq 45$ years old & 0.777 & 0.000 \\
\hline$>45$ years old & 0.532 & \\
\hline Sex & & 0.000 \\
\hline Male & 0.682 & 0.000 \\
\hline Female & 0.445 & \\
\hline
\end{tabular}

Table 5 presents the value of conformity between the neutrophil/lymphocyte ratio and the ChildTurcotte-Pugh classification. In all samples, moderate conformity was found between the neutrophil/lymphocyte ratio and the Child-Turcotte-Pugh classification $(\kappa=0.591, \mathrm{p}<0.001)$. Meanwhile, based on age and gender, it was found that age $\leq 45$ years and male gender had substantial conformity $(0.61 \leq \kappa \leq 0.80)$.

\section{Discussion}

Liver cirrhosis patients, according to age and gender, were found to be higher at age $>45$ years (74.4\%) and male gender (62.8\%). Women aged $\leq 45$ years have lower incidence of liver cirrhosis because the hormone estrogen, through $\operatorname{ER} \beta$ (Estrogen Receptor $\beta$ ), is able to inhibit the activation and proliferation of liver cells which triggers the deposition of collagen, so that the fibrosis process in liver cirrhosis can be inhibited. ${ }^{[29-33]}$

Most liver cirrhosis patients have a normal BMI (65.1\%). This is not in accordance with studies in the United States that found that there was a significant increase in BMI in patients with liver cirrhosis. ${ }^{[34]}$ Nutritional factors and the necessities fulfilled in Asia, especially developing countries together with 


\section{ISSN 25980580}

dominant factors such as infections (hepatitis B and C) cause lower mean BMI and even normal in liver cirrhosis patients in Indonesia. ${ }^{[3-4,35-36]}$

The distribution of hepatitis $\mathrm{B}$ in liver cirrhosis patients was found to be $51.2 \%$. This was in accordance with previous studies which obtained a dominant percentage of hepatitis B which was $24.60 \%$ and $78.2 \% .{ }^{[11,13]}$ However, liver cirrhosis patients who have hepatitis $\mathrm{C}$ have a mortality rate $25 \%$ higher than patients with hepatitis B. ${ }^{[15,29,37-38]}$

The results obtained in this study related to hepatocellular failure and portal hypertension manifestations included $41.9 \%$ incidence with esophageal varices, $11.6 \%$ with hepatic encephalopathy, and $58.1 \%$ with ascites. In the previous study, it was found that there were $6 \%$ of liver cirrhosis patients with esophageal varices, $10 \%$ with hepatic encephalopathy, and 50\% with ascites. ${ }^{[30,39]}$ From the two studies it was found that there were a significant increase in the incidence of esophageal varices. This was because the study was dominated by liver cirrhosis patients with the Child-Turcotte-Pugh classification C. Eighty-five percent of liver cirrhosis patients with the Child-Turcotte-Pugh C classification had esophageal varices. ${ }^{[40]}$

The percentage of patients with neutrophil/lymphocyte ratios of 3.1483-6.5208 was obtained to be $51.2 \%$ of the total sample. An increase in the neutrophil/lymphocyte ratio in patients with liver cirrhosis reflects an increase in neutrophils due to the chronic inflammatory process and a decrease in lymphocyte activity due to the suppression made by neutrophils through arginase, nitric oxide synthase (NOS), and reactive oxygen species (ROS). ${ }^{[7-8,11-16]}$

It was found that Child-Turcotte-Pugh C classification has results of 39.5\%. In previous studies, it was found that the sample with the Child-Turcotte-Pugh B classification dominated with a percentage reaching $44.1 \%$ and $56.94 \% .^{[41-43]}$ Liver cirrhosis patients with Child-Turcotte-Pugh C classification have a low survival rate. The 1-year and 2-year survival rate of liver cirrhosis patients with the ChildTurcotte-Pugh C classification were $45 \%$ and $35 \%$, respectively. ${ }^{[40]}$

Conformity between neutrophil/lymphocyte ratio and Child-Turcotte-Pugh classification in assessing severity of liver cirrhosis in all samples was found to be at moderate agreement. Some theories 
ISSN 25980580

suggest that there is an increase in neutrophils and decrease in lymphocytes so that the ratio between the two increases in liver cirrhosis patients. ${ }^{[7-8,16]}$ In liver cirrhosis, the necroinflammatory process activates liver stellate cells. The liver stellate cells then produce cytokines that activate neutrophils so that an inflammatory response occurs. However, hepatocyte death in liver cirrhosis causes produced cytokines cannot be detoxified. As a result, cytokines activate neutrophils persistently so that the number of neutrophils in the body increases. ${ }^{[8,11]}$

Meanwhile, neutrophils also have a mechanism to suppress lymphocyte formation through arginase, NOS, and ROS. Neutrophils have a high amount of arginase in azurophilic granules, whereas $\mathrm{T}$ cell activation depends on the availability of body arginine. The release of neutrophil arginase through degranulation or apoptosis causes a decrease in body arginine so $\mathrm{T}$ cell activation becomes inhibited. ${ }^{[12-}$ 14]

Based on age categories, conformity was found to be lower in the age group $>45$ years old (elderly). In elderly, there is a decrease in the function of the body's immune system (immunosenescence) so that the activation and migration of neutrophils to the site of infection is inhibited. ${ }^{[44-45]}$ In addition, when there are severe and long-term infections, elderly patients can experience neutropenia due to the continuous stimulation of the Granulocyte-Colony Stimulating Factor (G-CSF) to the Common Myeloid Progenitor. The impact of immunonescence on lymphocytes can also be seen from a decrease in lymphocyte levels in both B and T lymphocytes. [46]

By gender, a lower level of conformity between neutrophil/lymphocyte ratio and Child-TurcottePugh classification was obtained in women. The estrogen hormone in women is able to inhibit the activation and proliferation of liver cells that activate neutrophils through ER $\beta$ (Estrogen Receptor $\beta$ ). As a result, neutrophil levels in women with liver cirrhosis do not increase as much as in men, although worsening conditions in cirrhosis of the liver continue. ${ }^{[32]}$

The research conducted is limited on Cohen's Kappa conformity test because it only assess the compatibility between two methods which are not the gold standard. For this reason, it is recommended 
ISSN 25980580

that these two methods be tested and adjusted to the gold standard for examining the severity of liver cirrhosis in the future, which is liver biopsy.

\section{Conclusion}

Based on the results of this research on the conformity between neutrophil/lymphocyte ratio and Child-Turcotte-Pugh classification in assessing the severity of liver cirrhosis, it was concluded that there was a moderate conformity between neutrophil/lymphocyte ratio and Child-Turcotte-Pugh classification. Substantial conformity was found between neutrophil/lymphocyte ratio and Child-Turcotte-Pugh classification in the age group of $\leq 45$ years old and in male.

\section{Acknowledgement}

The researcher thanked Dr. Eny Rahmawati, M.Sc, Sp.PK (K) and dr. Emma Novita, M.Kes who was willing to give advice and guidance in completing the research report. Thank you to Dr. dr. Zen Hafy, M.Biomed who has been willing to give suggestions for improvements related to ethical feasibility in the preparation of this thesis. Thank you to the staff of Clinical Pathology Laboratory and the staff of Medical Record Department at RSUP Dr. Mohammad Hoesin Palembang who had helped in the process of collecting data.

\section{References}

[1] Nurdjanah S. Sirosis Hati. In: Buku Ajar Ilmu Penyakit Dalam. $6^{\text {th }}$ ed. Jakarta: Interna Publishing; 2014. p. 668-673.

[2] Vos T, Abajobir AA, Abate KH, Abbafati C, Abbas KM, Abate KH et al. Global, Regional, and National Incidence, Prevalence, and Years Lived with Disability for 328 Diseases and Injuries for 195 Countries, 1990-2016: "A Systematic Analysis for the Global Burden of Disease Study 2016". Elsevier Health Sciences 2017; 390(10100): 1211-1259.

[3] Tsochatzis EA, Bosch J, Burroughs AK. Liver Cirrhosis. Elsevier Health Sciences 2014; 383(9930): 1749-1761.

[4] World Health Organization. Age-Standardized Death Rates of Liver Cirrhosis, 2012. (Accessed July 22, 2018, at http://www.who.int/gho/alcohol/harms_consequences/deaths_liver_cirrhosis /en/).

[5] Malau DL. Karakteristik Penderita Sirosis Hati yang dirawat Inap di RSUD Sidikalang Tahun 2007- 


\section{ISSN 25980580}

2011. North Sumatera University. In press 2007.

[6] Perhimpunan Peneliti Hati Indonesia. Sirosis Hati. Indonesian Association for the Study of the Liver, 2013. (Accessed September 19, 2018, at http://pphi-online.org/alpha/?p=570)

[7] Albillos A, Lario M, Álvarez-Mon M. Cirrhosis-Associated Immune Dysfunction: "Distinctive Features and Clinical Relevance". Journal of Hepatology 2014; 61(6): 1385-1396.

[8] Noor MT, Manoria P. Immune Dysfunction in Cirrhosis. Journal of Clinical and Translational Hepatology 2017; 5(1): 50.

[9] Mak TW, Saunders ME, Jett BD. Primer to the Immune Response. Elsevier Health Sciences; 2013. p. 3-7.

[10]Price SA, Wilson LM. Patofisiologi: “Konsep Klinis Proses-Proses Penyakit”. $6^{\text {th }}$ ed. EGC; 2017.

[11]Probowati W, Bayupurnama P, Ratnasari N. Correlation between Neutrophil to Lymphocyte Ratio with Child Turcotte Pugh in Liver Cirrhosis Patients. The Journal of Internal Medicine 2016; 6(1): $28-35$.

[12] Sipeki N, Antal-Szalmas P, Lakatos PL, Papp M. Immune Dysfunction in Cirrhosis. World Journal of Gastroenterology 2014; 20(10): 2564.

[13] Kwon JH, Jang JW, Kim YW, Lee SW, Nam SW, Jaegal D et al. The Usefulness of C-Reactive Protein and Neutrophil-to-Lymphocyte Ratio for Predicting the Outcome in Hospitalized Patients with Liver Cirrhosis. BMC Gastroenterology 2015; 15(1): 146.

[14]Müller I, Munder M, Kropf P, Hänsch GM. Polymorphonuclear Neutrophils and T Lymphocytes: "Strange Bedfellows or Brothers in Arms?". Trends in Immunology 2009; 30(11): 522-530.

[15] Kalra A, Wedd JP, Bambha KM, Gralla J, Golden-Mason L, Collins C et al. Neutrophil-toLymphocyte Ratio Correlates with Proinflammatory Neutrophils and Predicts Death in Low Model for End-Stage Liver Disease Patients with Cirrhosis. Liver Transplantation 2017; 23(2): 155-165.

[16]Cai YJ, Dong JJ, Dong JZ, Chen Y, Lin Z, Song M et al. A Nomogram For Predicting Prognostic Value of Inflammatory Response Biomarkers in Decompensated Cirrhotic Patients Without Acuteon-Chronic Liver Failure'. Alimentary Pharmacology and Therapeutics 2017; 45(11): 1413-1426.

[17] Halazun HJ, Mergeche JL, Mallon KA, Connolly ES, Heyer EJ. Neutrophil-Lymphocyte Ratio as a Predictor of Cognitive Dysfunction in Carotid Endarterectomy Patients. Journal of Vascular Surgery 2014; 59(3): 768-773.

[18]Doubatty AC. Perbandingan Validitas Skor Mayo End Stage Liver Disease dan Skor Child-Pugh dalam Memprediksi Ketahanan Hidup 12 Minggu pada Pasien Sirosis Hepatis. Diponegoro University. In press 2009.

[19] Tohidinezhad F, Eslami S, Abu-Hanna A, Aliakbarian M. Model for End-Stage Liver Disease and Seven Derivations to Prioritize Liver Transplant Candidates: "Which is the Winner?". Experimental and Clinical Transplantation 2018.

[20]Peng Y, Qi X, Guo X. Child-Pugh versus MELD Score for the Assessment of Prognosis in Liver Cirrhosis: "A Systematic Review and Meta-Analysis of Observational Studies. Wolters Kluwer Health 2016; 95(8): 2877. 


\section{ISSN 25980580}

[21]Biselli M, Gitto S, Gramenzi A, Donato RD, Brodosi L, Ravaioli M et al. Six Score Systems to Evaluate Candidates with Advanced Cirrhosis for Orthotopic Liver Transplant: "Which is the Winner?". Liver Transplantation 2010; 16(8): 964-973.

[22] Friedman LS, Martin P. Handbook of Liver Disease. Elsevier Health Sciences; 2017.

[23]Peng Y, Li Y, He YH, Wei Q, Xie Q, Zhang L et al. The Role of Neutrophil to Lymphocyte Ratio for the Assessment of Liver Fibrosis and Cirrhosis: "A Systematic Review". Expert Review of Gastroenterology and Hepatology 2018; 12(5): 503-513.

[24]Biyik M, Ucar R, Solak Y, Gungor G, Polat I, Gaipov A et al. Blood Neutrophil-to-Lymphocyte Ratio Independently Predicts Survival in Patients with Liver Cirrhosis. European Journal of Gastroenterology and Hepatology 2013; 25(4): 435-441.

[25]Rice J, Dodge JL, Bambha KM, Bajaj JS, Reddy KR, Gralla J et al. Neutrophil-to-Lymphocyte Ratio Associates Independently With Mortality in Hospitalized Patients With Cirrhosis. Clinical Gastroenterology and Hepatology 2018.

[26] Odze RD, Goldblum JR. Odze and Goldblum Surgical Pathology of the GI Tract, Liver, Biliary Tract and Pancreas. Elsevier Health Sciences; 2014.

[27]Petrie A, Sabin C. 2013. Medical Statistics at a Glance. $2^{\text {nd }}$ ed. Blackwell Publishing; 2013.

[28]Dahlan, M. S. 2011. Statistik untuk Kedokteran dan Kesehatan. Penerbit Salemba Medika, Jakarta, Indonesia, hal. 106-111.

[29]Leithead JA, Rajoriya N, Gunson BK, Ferguson JW. Neutrophil-to-Lymphocyte Ratio Predicts Mortality in Patients Listed for Liver Transplantation. Liver International 2015; 35(2): 502-509.

[30]Zhang H, Sun Q, Mao W, Fan J, Ye B. Neutrophil-to-Lymphocyte Ratio Predicts Early Mortality in Patients with HBV-Related Decompensated Cirrhosis. Gastroenterology Research and Practice 2016.

[31] He Q, He Q, Deng Y, He Y, Xie L, Li T et al. The Relationship Between Inflammatory Marker Levels and HBV-Related Cirrhosis Severity. International Journal of Clinical and Experimental Medicine 2016; 9(11): 22200-22205.

[32]Zhang B, Zhang CG, Ji LH, Zhao G, Wu ZY. Estrogen Receptor $\beta$ Selective Agonist Ameliorates Liver Cirrhosis in Rats by Inhibiting the Activation and Proliferation of Hepatic Stellate Cells. Journal of Gastroenterology and Hepatology 2018; 33(3): 747-755.

[33]Floch MH, Floch NR, Kowdley K. Netter’s Gastroenterology. Elsevier Health Sciences; 2010.

[34] Wong RJ, Aguilar M, Cheung R, Perumpail RB, Harisson SA, Younossi ZM et al. Nonalcoholic Steatohepatitis is the Second Leading Etiology of Liver Disease among Adults Awaiting Liver Transplantation in the United States. Elsevier Gastroenterology 2015; 148(3): 547-555.

[35] Yen YH, Chang KC, Tsai MC, Tseng PL, Lin MT, Wu CK et al. Elevated Body Mass Index is a Risk Factor Associated with Possible Liver Cirrhosis across Different Etiologies of Chronic Liver Disease. Journal of the Formosan Medical Association. Elsevier 2018; 117(4): 268-275.

[36] Jarnagin WR. Blumgart's Surgery of the Liver, Pancreas and Biliary Tract. Elsevier Health Sciences; 2016. 


\section{ISSN 25980580}

[37] Stanaway JD, Flaxman AD, Naghavi M, Fitzmaurice C, Vos T, Abubakar I et al. The Global Burden of Viral Hepatitis from 1990 to 2013: "Findings from the Global Burden of Disease Study 2013". Elsevier 2016; 388(10049): 1081-1088.

[38] Genda T, Ichida T, Sakisaka S, Tanaka E, Mochida S, Ueno Y et al. Survival in Patients with ChildPugh Class C Cirrhosis: "Analysis of the Liver Transplant Registry in Japan. Hepatology Research Wiley Online Library 2017; 47(11): 1155-1164.

[39] Baldassarre M, Domenicali M, Naldi M, Laggetta M, Giannone FA, Biselli M et al. Albumin Homodimers in Patients with Cirrhosis: "Clinical and Prognostic Relevance of a Novel Identified Structural Alteration of the Molecule". Nature Publishing Group 2016; 6: 35987-35995.

[40] Qayed E, Srinivasan S, Shahnavaz N. Sleisenger and Fordtran's Gastrointestinal and Liver Disease Review and Assessment. Elsevier Health Sciences; 2016.

[41]Kaplan DE, Dai F, Aytaman A, Baytarian M, Fox R, Hunt K et al. Development and Performance of an Algorithm to Estimate the Child-Turcotte-Pugh Score from a National Electronic Healthcare Database. Elsevier Clinical Gastroenterology and Hepatology 2015; 13(13): 2333-2341.

[42]Peng Y, Qi X, Dai J, Li H, Guo X. Child-Pugh versus MELD Score for Predicting the in-hospital Mortality of Acute Upper Gastrointestinal Bleeding in Liver Cirrhosis. International Journal of Clinical and Experimental Medicine 2015; 8(1): 751-757.

[43] Fortune BE, Garcia-Tsao G, Ciarleglio M, Deng Y, Fallon MB Sigal S et al. Child-Turcotte-Pugh Class is Best at Stratifying Risk in Variceal Hemorrhage: "Analysis of a US Multi-Center Prospective Study". Journal of Clinical Gastroenterology 2016; 51(5): 446-453.

[44] Chen MM, Palmer JL, Plackett TP, Deburghgraeve CR, Kovacs EJ. Age-Related Differences in the Neutrophil Response to Pulmonary Pseudomonas Infection. Experimental Gerontology Elsevier 2014; 54(1): 42-46.

[45]Drew W, Wilson DV, Sapey E. Inflammation and Neutrophil Immunosenescence in Health and Disease: "Targeted Treatments to Improve Clinical Outcomes in the Elderly. Experimental Gerontology Elsevier 2018; 105: 70-77.

[46]Fuentes E, Fuentes M, Alarcón M, Palomo I. Immune System Dysfunction in Elderly. Annals of the Brazilian Academy of Sciences 2017; 89(1): 285-299. 